Pak. j. sci. ind. res. Ser. A: phys. sci. 2019 62A(1) 48-51

\title{
Effect of Cross Linker Treatment on Dimensional and Mechanical Properties of Knitted Fabrics
}

\author{
Tauheed Ahmed, Farida Irshad*, Assad Farooq, Muhammad Azeem Ashraf and Nasir Mahmood \\ Department of Fibre and Textile Technology, University of Agriculture, Faisalabad, Pakistan
}

(received March 3, 2017; revised May 26, 2018; accepted June 6, 2018)

\begin{abstract}
The aim of this study is to evaluate the effect of crosslinker concentrations on dimensional and mechanical properties of $100 \%$ cotton knitted structures. After crosslinker treatment at two different concentrations, it was observed that fabric shrinkage and spirality were effectively controlled with the increased amount of crosslinker. It was also observed that varying cross-linker concentrations have the most significant impact on the dimensional control of single jersey knitted fabric as compared to pique and fleece. The crosslinking of reactive groups present in the cellulosic structure resulted in decrease in bursting strength of all knitted fabrics. However, the decrease in bursting strength was minimized by increasing softener concentration.
\end{abstract}

Keywords: dimensional instability, spirality, compactness, loop length, cross linker

\section{Introduction}

Cotton fibres can be converted into fabric by using different fabric manufacturing techniques but the two most commonly used methods are weaving and knitting (Schwartz, 2008). The molecular structure of cellulosic material causes wrinkling and creasing problem in woven fabrics. Cotton fibres consist of strands of polysaccharide cellulose that are stabilized by hydrogen bonding (Schindler and Hauser, 2004). In wet state, water molecules penetrate inside individual polysaccharide chains and disturb the hydrogen bonding of polymer chains, which results in shifting of original positions of chains (Quaynor et al., 2000). On drying, hydrogen bonds reform at their shifted positions and wrinkling takes place on the surface of fabric.

Knitted fabrics are produced by inter looping of yarns. In comparison with woven fabrics, knitted fabrics show better stretch and recovery, resilience, porosity, air permeability, softness and warmth (Kane et al., 2007). However, the major shortcoming of knitted fabrics is the lower dimensional stability owing to the instability in their loop dimensions, which may occur due to fibre swelling in wet state, higher yarn spinning tensions and internal stresses in textile wet processing (Sakthivel, and Anbumani, 2012; Sharma et al., 1985).

Dimensional stability of a knitted fabric can be controlled by changing the fibres, yarn parameters (twist, bulk,

*Author for correspondence:

E-mail: faridairshad45@gmail.com count and finish), knitting parameters (course per inch, wales per inch, loop length and fabric weight) and post knitting finishes (enzyme and chemical) (Badr et al., 2016). Fabric with improved dimensional stability can also be achieved by using elastomeric yarns. However, the product does not remain cost efficient due to high price elastane and additional heat setting process (Safdar et al., 2014; Senthilkumar, 2012). Shrinkage control with a mechanical compactor is also a successful application but it gives limited shrinkage control, which may not last after 4-5 washes (Mikuèionienë and Laureckienë, 2009).

The most durable and efficiently used technique for knitted fabric dimensional control is resin finishing. Dimethylol dihydroxyethylene urea (DMDHEU) is the most commonly used crosslinking agent in textile industry. DMDHEU resin crosslinks the -OH group on the polymer chain of cotton fabric. This crosslinking locks the -OH group of the cellulose allowing the yarn to maintain their loop shape even after repeated washing and further processing. Thus, the dimensional stability is improved by maintaining the shape of loop in knitted structure. However, the DMDHEU has negative influence on the bursting strength of knitted fabric (Ashraf et al., 2016; Dehabadi, 2013). Figure 1 shows the crosslinking of DMDHEU cross linker with cotton.

This study provides the information regarding the effect of resin finish concentrations on the shrinkage, spirality and bursting strength of different knitted fabrics. 


\section{Materials and Methods}

The $100 \%$ cotton single jersey, honeycombed pique and fleece knitted fabrics used in this study were obtained from Klash Textile Mill, Faisalabad Pakistan. The Crosslinker (KNITTEX RCT), KNITTEX CATALYST MO LIQ and Softener (TURPEX ACN) were obtained from Huntsman Textile Effects Pakistan (Private) Limited. Finishing solutions were prepared by using different concentrations of crosslinker and catalyst as given in Table 1. Then the fabrics were impregnated with finishing solution by using padder (Advance System Logic, Pakistan) at a 5 bar pressure and speed of $5 \mathrm{rpm}$. Afterward, fabrics were dried at $120^{\circ} \mathrm{C}$ for 2 min and then cured at $170{ }^{\circ} \mathrm{C}$ for $3 \mathrm{~min}$ on stenter (Roaches by Advanced Dyeing Solutions Limited, UK). Different physical properties of fabrics were determined by following the ISO standards i.e., dimensional stability (ISO, 2007) was measured on Wascator (SDL Atlas, USA), skewness change in fabric (BSI, 1990) and bursting strength (ISO, 1999) were measured on Pneumatic Bursting Strength Tester (SDL Atlas, USA).

\section{Results and Discussion}

Shrinkage. Figure 2 represents the shrinkage \% in terms of length and width of single jersey, pique and fleece fabrics at different cross linker concentrations.

In knitted fabrics, open structure is the basic reason for their lower dimensional stability. Secondly, the cellulosic structure contains reactive hydroxyl groups that are prone to break bond from one place and make new bonds on another place, which results in variation of fabric dimensions. A significant decrease in shrinkage $\%$ was observed after application of DMDHEU in different concentrations on different knitted structures. The most prominent effect was seen on single jersey where shrinkage $\%$ decreased from 7 to $1.1 \%$ in length and width direction with $5 \%$ resin concentration. More decrease in shrinkage was observed by treatment with $10 \%$ crosslinker concentration. Hence, by increasing the concentration of crosslinker more reactive hydroxyl

Table. Resin finish recipe

\begin{tabular}{lll}
\hline \hline Chemicals & Commercial names & Concentration \\
\hline Cross linker & DMDHEU (KNITTEX ${ }^{2}-$ RCT $)$ & $50 \mathrm{~g} / \mathrm{L}, 100 \mathrm{~g} / \mathrm{L}$ \\
Catalyst & (KNITTEX ${ }^{2}$-CAT MO/LIQ) & $25 \mathrm{~g} / \mathrm{L}, 50 \mathrm{~g} / \mathrm{L}$ \\
Softener & $\left(\right.$ TURPEX ${ }^{\circledR}$ CAN) & $10 \mathrm{~g} / \mathrm{L}$ \\
\hline \hline
\end{tabular}

groups in the structure of cellulose were masked and less shrinkage $\%$ achieved. The same trend of shrinkage control was observed in pique fabric. Fleece fabric showed 4 and $3.7 \%$ shrinkage in length and width direction, respectively as an evidence of its better dimensional stability. The reason behind the better dimensional stability of fleece is its compact structure with less

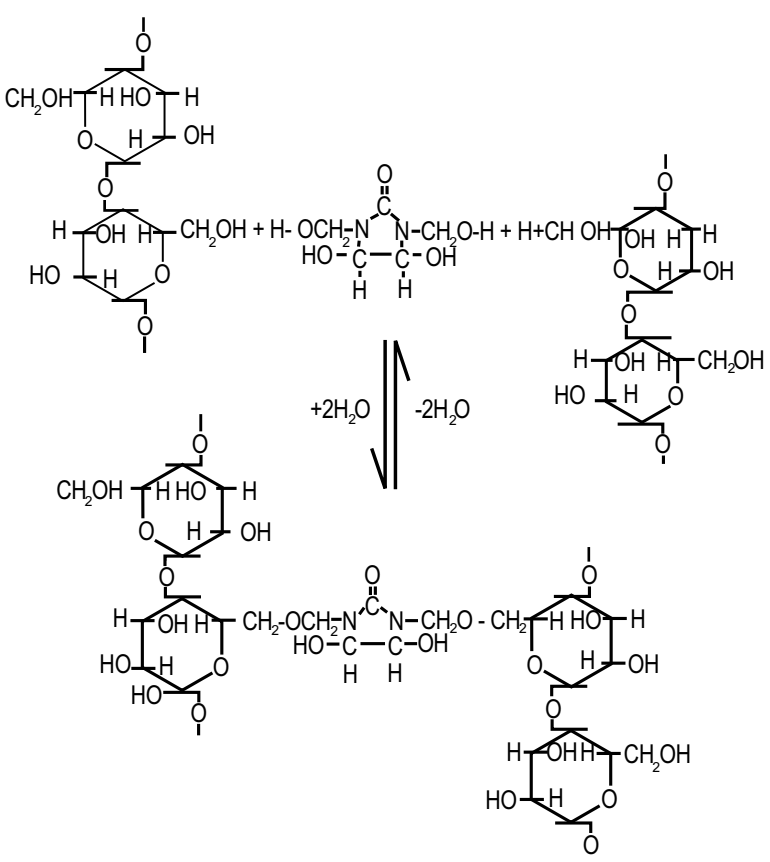

Fig. 1. Crosslinking of DMDHEU with cotton.

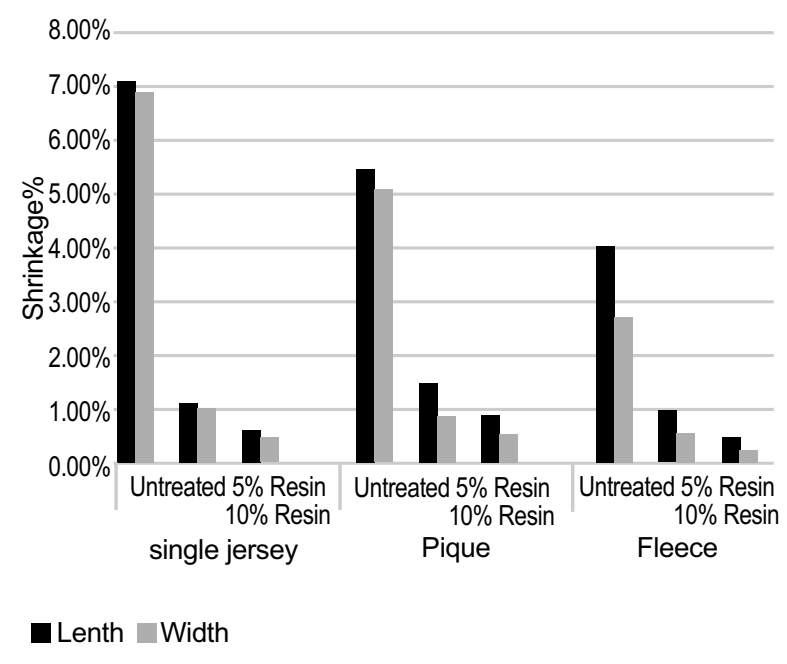

Fig. 2. Effect of resin finish treatment on shrinkage $(\%)$. 
flexibility and elasticity. Moreover, its knits are shorter in length and tighter. However, the crosslinker provided the sufficient impact on reducing the shrinkage $\%$ of fleece fabric but it is not as significant as on single jersey and pique fabrics.

Spirality. Spirality $\%$ of different knitted fabrics before and after treatment has been presented in Fig 3 .

Before the application of crosslinker, single jersey fabric showed the highest spirality percentage $4.15 \%$ (more than the acceptable limit). The higher spirality $\%$ of the single jersey was due to its open structure and cellulose reactive groups. To make the single jersey fabric more comfortable, long and loose stitches were imparted in its structure that improved the shrinkage and spirality $\%$. Single jersey structure was stabilized by using different crosslinker concentrations and a significant

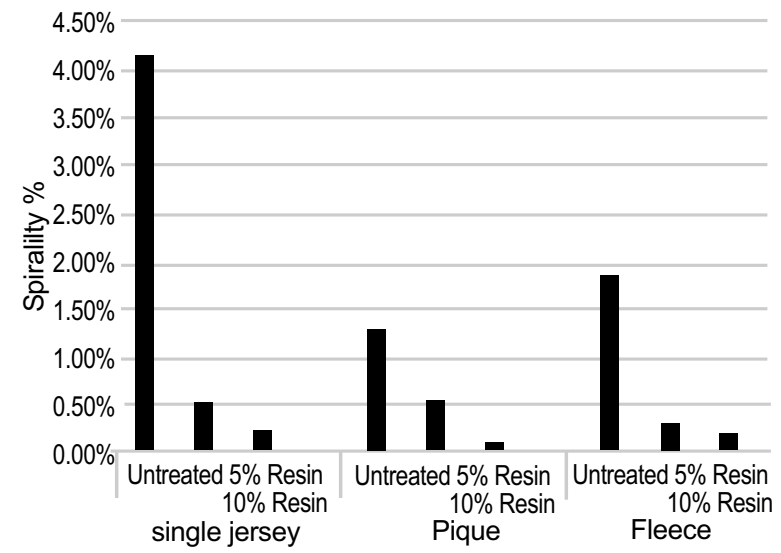

Fig. 3. Effect of resin finish treatment on spirality $(\%)$.

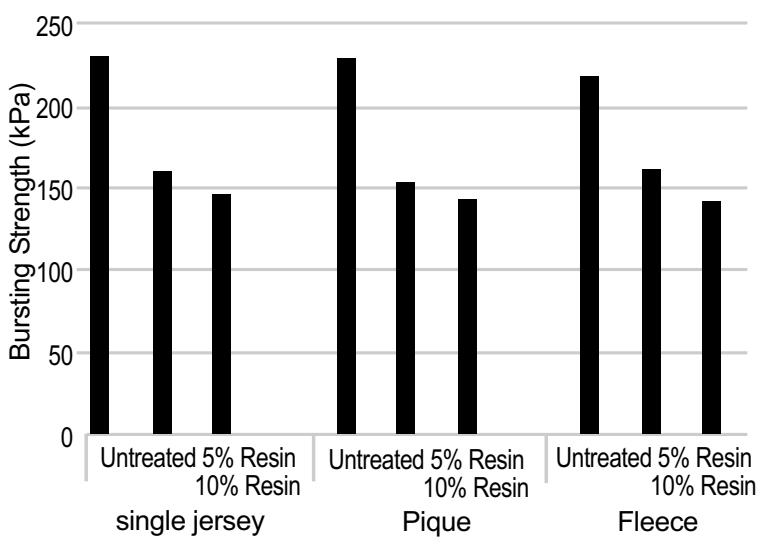

Fig. 4. Effect of resin finish treatment on bursting strength. decrease in spirality \% was noticed. Pique and fleece fabrics possess lesser spirality $\%$ as compared to single jersey which was further reduced by using crosslinker.

Bursting strength. Figure 4 depicts decrease in bursting strength of different knitted fabrics after application of crosslinker.

The decrease in bursting strength was due to cross linker's ability to restrict the mobility of fibers in the fabric structure through chemical bonding with the reactive groups of the cellulose. A significant decrease in bursting strength was observed for all three structures after application of resin finish.

\section{Conclusion}

The study revealed that fabric shrinkage and spirality were effectively controlled by application of crosslinker on the surface of the fabric. Fleece fabric has most dimensionally stable structure due to its compactness. The single jersey and pique are dimensionally unstable fabrics due to loose stitches and open structures. Resin finish application showed the most significant impact on shrinkage and spirality control of single jersey fabric by creating a three-dimensional crosslinking network on the surface of the fabric and by masking the reactive hydroxyl groups present in the cellulosic structure. However, this crosslinking network had prohibited the movement of fibre which resulted in strength loss of all three knitted fabrics. The loss in bursting strength can be controlled by increasing the softener concentration in finishing the recipe.

Conflict of Interest. The authors declare no conflict of interest.

\section{References}

Ashraf, M., Irshad, F., Umar, J., Farooq, A., Ashraf, M.A. 2016. Development of a novel curing system for low temperature curing of resins with the aid of nanotechnology and ultraviolet radiation. RSC Advances, 6: 81069-81075.

Badr, A.A., Hassanin, A., Moursey, M. 2016. Influence of Tencel/cotton blends on knitted fabric performance. Alexandria Engineering Journal, 55: 24392447.

BSI, 1990. Methods for determination of bow, skew and lengthway distortion in knitted fabrics (BS 2819:1990), British Standards Institution, London, England. 
Dehabadi, V.A., Buschmann, H.J., Gutmann, J.S. 2013. Durable press finishing of cotton fabrics: an overview. Textile Research Journal, 83: 1974-1995.

ISO, 2007. Textiles-determination of dimensional change in washing and drying (ISO 5077:2007), International Organization for Standardization, Geneva, Switzerland.

ISO, 1999. Textiles-bursting properties of fabrics, Part-1: Hydraulic method for determination of bursting strength and bursting distension (ISO 13938-1:1999), International Organization for Standardization, Geneva, Switzerland.

Kane, C.D., Patil, U.J., Sudhakar, P. 2007. Studies on the influence of knit structure and stitch length on ring and compact yarn single jersey fabric properties. Textile Research Journal, 77: 572-582.

Mikuèionienë, D., Laureckienë, G. 2009. The influence of drying conditions on dimensional stability of cotton weft knitted fabrics. Materials Science, 15: 64-68.

Quaynor, L., Takahashi, M., Nakajima, M. 2000. Effects of laundering on the surface properties and dimensional stability of plain knitted fabrics. Textile Research Journal, 70: 28-35.
Safdar, F., Hussain, T., Nazir, A., Iqbal, K. 2014. Improving dimensional stability of cotton knits through resin finishing. Journal of Engineered Fibers and Fabrics, 9: 28-35.

Sakthivel, J.C., Anbumani, N. 2012. Dimensional properties of single jersey knitted fabrics made with new and regenerated cellulosic fibers. Journal of Textile and Apparel, Technology and Management, 7: 110.

Schindler, W.D., Hauser, P.J. 2004. Chemical Finishing of Textiles, pp. 224, $1^{\text {st }}$ edition, Woodhead Publishing Ltd., Cambridge, England.

Schwartz, P. 2008. Structure and Mechanics of Textile Fibre Assemblies, pp. 264, $1^{\text {st }}$ edition, Woodhead Publishing Ltd., Cambridge, England.

Senthilkumar, M., Sounderraj, S., Anbumani, N. 2012. Effect of spandex input tension, spandex linear density and cotton yarn loop length on dynamic elastic behavior of cotton/spandex knitted fabrics. Journal of Textile and Apparel, Technology and Management, 7: 1-16.

Sharma, I.C., Ghosh, S., Gupta, N.K. 1985. Dimensional and physical characteristics of single jersey fabrics. Textile Research Journal, 55: 149-156. 